\title{
Reference Model Framework for Production of Small Series of Innovative and Fashionable Goods in Manufacturing Networks
}

\author{
Andrea Zangiacomi, Rosanna Fornasiero, João Bastos, Américo \\ Azevedo, Valentina Franchini and Andrea Vinelli
}

\begin{abstract}
In fashion business, consumer needs and expectations of specific target groups - such as elderly, obese, disabled, or diabetic persons-are arising as challenging opportunities for European companies that are asked to supply small series of innovative and fashionable goods of high quality, affordable price and eco-compatible. This paper aims at proposing a reference model to support collaborative supply networks in addressing the need for Fashionable and Healthy Clothing and Footwear products. In particular this work describes the implementation of the model in a real case highlighting the developments and changes implied at network level.
\end{abstract}

\section{Introduction}

Recent years have stressed the need of re-inventing the enterprise concept and the path to achieve competitive advantage. Moreover, the global financial crisis coupled with the remarkable increase of oil and energy prices has forced managers to dramatically change the way they perform business. The flows of money shrank and consequently the flows of products and services have considerably decreased. Enterprise managers are now forced to address market and especially individual customers with augmented care by putting more emphasis on the service levels they provide, by reducing response times and by tackling customers' specific

\author{
A. Zangiacomi · R. Fornasiero ( $\square)$ \\ ITIA-CNR, Istituto di Tecnologie Industriali ed Automazione, Milano, Italy \\ e-mail: rosanna.fornasiero@itia.cnr.it \\ J. Bastos · A. Azevedo \\ INESC TEC, Faculdade de Engenharia da Universidade do Porto, Porto, Portugal \\ V. Franchini · A. Vinelli \\ Dipartimento di Tecnica e Gestione dei Sistemi Industriali, \\ Università degli Studi di Padova, Vicenza, Italy
}

\footnotetext{
A. Azevedo (ed.), Advances in Sustainable and Competitive Manufacturing Systems, Lecture Notes in Mechanical Engineering, DOI: 10.1007/978-3-319-00557-7_105,

(C) Springer International Publishing Switzerland 2013
} 
needs. This confluence of trends has led managers moving from a traditional functional focus in the way they conduct business into a more holistic approach in addressing the overall supply chain. As a consequence, it is emerging at industrial level the adoption of collaborative strategies for the production of small series of high-customized complex products with increased emphasis in the service levels and the reduction of the response time. Along this vein, consumer needs and expectations of specific target groups - such as elderly, obese, disabled, or diabetic persons - are arising as challenging opportunities for European companies which are asked to supply small series of innovative and fashionable goods of high quality, affordable price and eco-compatible in short time and with high service levels. In order to design, develop, produce and distribute such products, a new framework, and related components for collaborative networking are necessary.

The main objective of this paper is to describe an innovative Reference Model (RM) for manufacturing networks in the fashion sector and its implementation in a real case to support the production of small batches addressing the specific needs of the consumer target groups considered. The aim of the proposed reference model is to support and guide footwear and garments network stakeholders in modeling, designing and configuring the combination of processes, functions, activities, relationships and paths along which products, services, and information flow in and among companies.

The focus of the model is not on cost optimization strategies but on improving the responsiveness of the supply chain (SC) according to the agile paradigm. When dealing with product customization, the modularization of product components bring to split between standards components, where the focus is on cost reduction and which can be produced in advance and stocked, and other more important components, which are customized ones. These components are crucial for the product characterization and have to be realized according to higher quality levels only when the order for a specific product is made: this requires a deep coordination in the production chain between partners and short lead times. For this reason, in order to optimize the management of these components during design and production, it is necessary to apply the agile model for SC. The definition of the decoupling point is important to define how agile should be the SC and to identify the right partners.

In the following chapters it is presented the Reference Model framework highlighting the addressed methodology, the RM peculiarities targeted on company from the TCFI sector and its instantiation in a specific real case.

\section{Literature Review}

Nowadays competition within the fashion sector is among global networks and the key issues are on how to develop and implement innovative managerial models and methods to support collaborative practices, especially among SMEs, which represents the majority of companies in TCFI [1, 2]. 
A new level of complexity is arising, given the fact that competition as well as collaboration schemes are transitioning from company versus company, to supply network versus supply network. As a consequence, the management of both interorganizational and inter-supply chain processes and information is becoming even more critical in order to assure rapid responses, eco-sustainability and quality assurance of products and processes.

Recent research in the field of supply networks addressed different forms of business networks. They are distinguished, for example, by the value chain orientation (horizontal, vertical, lateral), life span (long-term vs. short-term), degree of virtualization or hierarchical structure (hierarchical vs. non-hierarchical networks) [3]. The current market asks for flexible organizational structures, which quickly adapt to new business requirements and sustainability challenges. These new demands are forcing business networks to have shorter life-time existence and take advantage of new infrastructure technologies supporting distributed information systems and knowledge.

The paradigm of demand-driven supply networks is emerging in literature as a collaborative approach answering to consumer's needs and expectations $[4,5,6]$. This implies different approaches to market based not only on traditional sales channels (as shops or retailers) but more and more on an Internet mediated contact with consumers both for product conception and for sales.

At the same time, the market increasingly values collaborative networks that endorse the sustainability challenges. Moreover, as Adler [7] effectively discussed, the new enlarged structures, characterized by high cognitive content exchanges, can no longer be coordinated by traditional hierarchy/market instruments as they require trust to share knowledge and leverage on external, updated and complementary competencies.

After a deep analysis of some of the most important supply network reference models in literature-among others the Value reference model, the SCOR model and the Y-Cim model — the SMART model proposed by Filos and Banhan [8] has been selected as the starting point to map practices to be implemented at different levels along the following three main dimensions:

1. Knowledge: to map partners' competencies to be shared within the network in terms of products and processes;

2. Information and Communication Technologies (ICTs): to support the requirements for the implementation of ICT services at different process levels along the network;

3. Organizational: to provide specifications of the organizational changes for SMEs for structuring supply networks in small series production.

For the scope of this study a new dimension, coherent with the eco-efficiency objective, has been added to the model, namely Sustainability. This dimension is intended to support companies aiming to create sustainable networks, in developing an eco-compatible approach for their products and processes. 


\section{Footwear Sector Analysis}

In order to conceptually build a structure and validate a reference model framework addressing supply networks for fashionable and innovative products, it is necessary to collect and evaluate relevant field data and perform specific industrial case studies in different sectors and scenarios. The research approach selected is based on empirical fieldwork based on cross-case analysis which was chosen due to its suitability in addressing both qualitative and quantitative data and also social and behavioral aspects.

The considered companies from the fashion sector have been selected both among large companies and SMEs to analyse practices that can be transferred and applied to SME networks. The sample was created adopting theoretical sampling [9], and multiple investigators have been used to reduce bias and produce more reliable data [10, 11]. For each selected company an "AS IS" business process analysis was conducted through focused interviews and BPMN (Business Process Modeling Notation) representation to collect and formalize a rich set of data, both qualitative and quantitative. Furthermore, the requirements of each company were pointed out and analyzed in detail to draw the relevant characteristics, procedures, and techniques along their supply network. Cross-case analysis among the different companies of the same sector, allowed to compare companies' behaviors and understand collaboration mechanisms. For each analysis the four main dimensions of the SMART network model (knowledge, ICT, organizational, and sustainability) have been considered to understand which are the main characteristics of the sector (and also the strength and weakness) along all of them.

The fashion sector is characterized by volatile product demand and need of quick planning and production responses. Footwear in particular presents a really fragmented and rigid scenario, constituted by many specialized knowledge intensive companies most of the time grouped in industrial districts. Each phase of their production process is deeply characterized by traditional approaches always oriented to batch quantities and local maximization [6]. Based on the previously defined four dimensions, the cross-case analysis for the fashion footwear companies resulted in the following outcomes:

Knowledge: innovation is strongly customer driven, and especially in the latest years companies started to manage smaller production lots with a higher level of customization (based both on aesthetic and functional features) to face competitively the market. Evolving customer needs influence production with requests of personalization and customization affecting components and/or materials, but not the structure of the products, thus according to the "best fit" approach. Design capabilities and an established know-how on production techniques owned by companies represent an important competitive advantage for them.

ICTs: manufacturing processes of fashion footwear companies are more and more supported by CAD based design starting from the $2 \mathrm{D}$ drafts creation to the 3D development of models and sizes. Other production activities are also supported by IC technologies, for example the laser cutting and leather marking. 
However, several other phases, in particular concerning the smallest companies, are still characterized by traditional approaches and a huge effort is necessary to drive improvement towards automation and real-time monitoring along networks.

Organizational: Long-term relationships are established and suppliers are involved in the design phase and during product industrialization, since each of them has to develop its own component according to the information received by the shoe producer. Suppliers provide both standard components and exclusive products (i.e. soles and heels can be patented). Several phases of the production processes are commonly outsourced: cutting, stitching and often final assembly. Companies develop a strong relationship with their outsourcers as well to guarantee the highest quality level to their customers, and benefit from their availability and flexibility along the season, according to collected orders variation.

Sustainability: large enterprises have started to implement sustainable practices moving to eco-products and eco-processes. Nike, for example, developed an environmental apparel design tool to create eco friendly products; Adidas implemented a test to check the sustainability of raw materials and Timberland developed a Green Index to compare the environmental impact of their products.

\section{Reference Model Framework for Manufacturing Networks}

The proposed Reference Model (RM) Framework aims to support fashion companies in defining collaborative networks for the production of healthy and fashionable products and is based on matching theoretical approaches from literature and emerged needs from the analyzed business cases along three different levels: strategical, tactical, and operative. Figure 1 presents the overall conceptual view of this proposed RM mapping its three decisional levels with the four structural dimensions.

For what concerns the strategic level, the business model framework proposed by Osterwalder [12] and extended by Loss and Crave [13] in combination with the model improved by Romero et al. [14], and integrating also approaches from Plantin [15] to fit to Collaborative Networks, is here applied. This model maps the most important building blocks that influence the definition of the value proposition when working in networks. In Fig. 1 the scheme of the model is represented.

In the RM strategic level, a set of characterizing elements for the adequate definition of the supply chain strategy for fashion SMEs based on the data collected in the cross-case analysis and the related research literature were identified according to the dimensions of the building blocks.

In the tactical level of the RM, the most important processes critical for the implementation of the business model have been identified according to the requirements mapped in the business case analysis. These processes have been formalized according to the Business Process Model Notation (BPMN). At the 


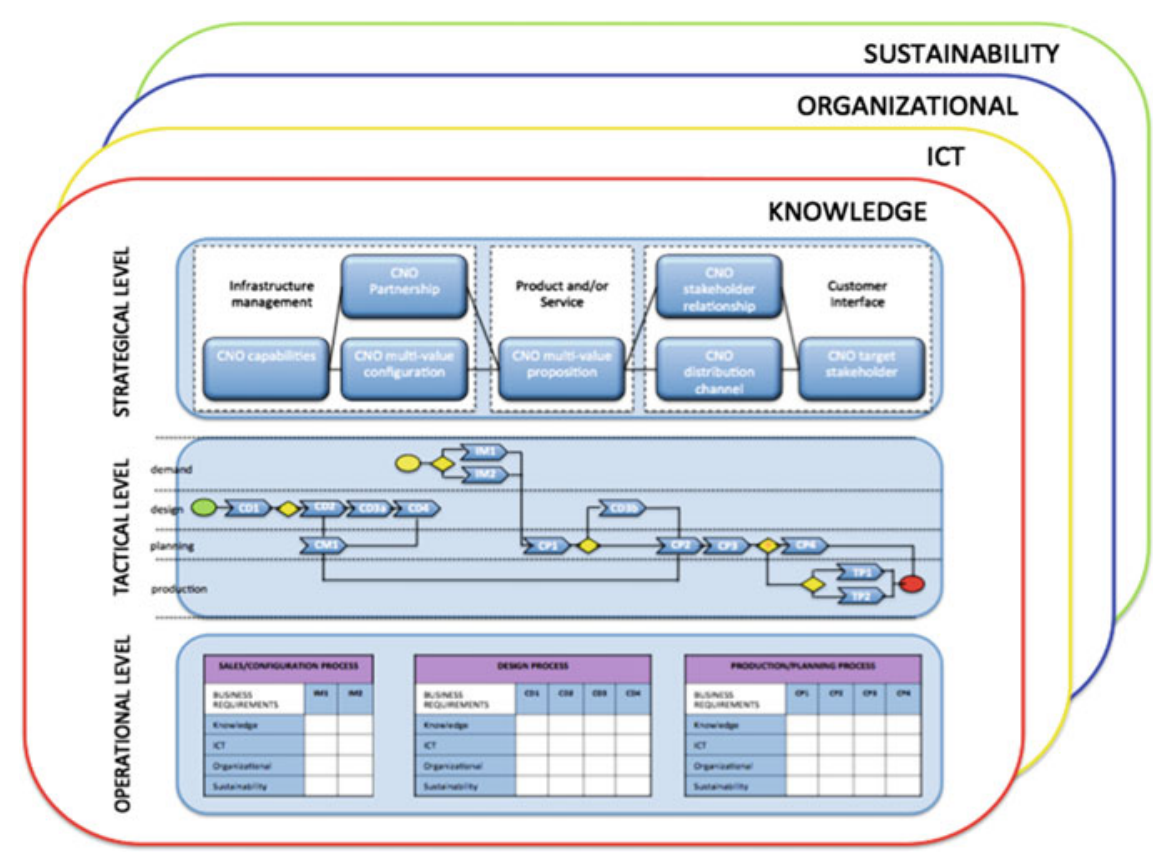

Fig. 1 Reference model context diagram

tactical level a high level view summarizes the whole process flow, highlighting the sequence and the interrelations between the different sub processes involved in each phase. Moreover a set of tools to support collaboration between the different stakeholders of the network, both from the customer side (B2C) and from the supply chain side (B2B), are also mapped along all the business processes.

The operative level guides companies in the implementation of the business processes with specific practices, KPIs, templates and all information, and materials useful to support the processes considered and the management of all related activities.

\section{Implementation of the Model: A Case Study}

This section presents the implementation in the footwear industry of the RM as an application example. The model can be instantiated to different types of business, both traditional companies, where relationship with customer passes by retailers and distributors, and companies with on online business (B2C), where the direct contact via web gives the possibility to create easily new configuration spaces and to understand customer's needs without intermediaries. The most important features of the reference model are here described for a footwear traditional company. 
In order to apply the Reference Model developed and presented in the previous paragraphs it has been chosen a worldwide company operating with own brand in the footwear fashion market, which main products are highly refined shoes for women. This manufacturing firm externalizes some production phases (around 100 partners, both suppliers and outsourcers) maintaining the core competences along the supply network (i.e. design skills for shoes and components, manufacturing skills and distribution channels) and adding the most of the value to the final products. Customization nowadays regards only aesthetical and material configurations. For these reasons it could be considered as the starting point to build up the whole supply network. We will refer to this company as company A in the following sections.

\subsection{Strategical Level}

The work consisted in the definition of the business model of company A network according to the different building blocks identified in the strategic level of the RM and in the identification of the implications on the supply network. In the table below a short summary of the most important characteristics related to the building blocks of the new business model is depicted as a guideline for companies of the fashion sector. For each building block it is shortly described which are the dimensions to be involved in the process to allow a fashion company to enter a market segment to offer innovative and fashionable products for target groups like diabetics, elderly, and obese people (Table 1).

\subsection{Tactical Level}

The tactical level has been instantiated to the footwear scenario according to specific requirements and needs collected and analyzed with the company and all the partners of the collaborative network. Within the whole process flow five different phases have been identified and analyzed, namely Market interaction, Collaborative design, Development and Customization, Network configuration, Supply network co-planning, and coordination and Customized production. Table 2 here below summarizes, as an example, the different processes included and the related four dimensions considered in the model for two of them, highlighting for each process, the actors involved as well as the tools used. An innovative aspect considered in the Reference Model is the capability to consider the interaction with customer (even end-consumer) during product design and configuration and the strict collaboration both with suppliers and technology providers all along the process flow. 
Table 1 Implementation of the strategic level

\begin{tabular}{|c|c|}
\hline Building blocks & Dimensions (organizational, ICT, knowledge, sustainability) \\
\hline Target stakeholder & $\begin{array}{l}\text { Target stakeholders are Podiatric centers and retailers already selling } \\
\text { orthopaedic shoes. In the long term there can be multi-brand } \\
\text { independent retailers selling specific TG shoes together with dedicated } \\
\text { shoes. } \\
\text { To reach the stakeholders, companies need to focus on improving ICT } \\
\text { dimensions with new tools to support customers during the sales } \\
\text { process, both in shop (foot measurement, product configuration) and } \\
\text { online sales. Moreover knowledge dimension needs to be reinforced } \\
\text { with a deep analysis of the target groups requirements }\end{array}$ \\
\hline $\begin{array}{l}\text { Multi-value } \\
\text { proposition }\end{array}$ & $\begin{array}{l}\text { Footwear with fashion and functional features specific for each target } \\
\text { groups. The multi-value proposition is based on the collaboration of all } \\
\text { the stakeholders for the design and realization of the new product } \\
\text { concept. The multi value proposition implies the transversal application } \\
\text { of new approaches along the four dimensions: knowledge-ICT- } \\
\text { organizational-sustainability }\end{array}$ \\
\hline $\begin{array}{l}\text { Distribution } \\
\text { channel }\end{array}$ & $\begin{array}{l}\text { Distribution channel can be based on: } \\
\text { - existing and new retailers (big/small) } \\
\text { - Own shops } \\
\text { - Podiatric centers } \\
\text { Distribution channels need to be improved both in terms of organization } \\
\text { (closer relationship to collect customized orders) and in terms of ICT } \\
\text { dimension since it implies the application of new tools for product } \\
\text { configuration allowing customer from TGs to have dedicated } \\
\text { configuration space taking into consideration the specific requirements } \\
\text { both in terms of functional and aesthetic variants of the product }\end{array}$ \\
\hline $\begin{array}{l}\text { Stakeholder } \\
\quad \text { relationship }\end{array}$ & $\begin{array}{l}\text { Creation of trusted relationships can be achieved having a clear and updated } \\
\text { vision of market needs and building an effective communication } \\
\text { channel with customers. This can be done with a set of structured } \\
\text { actions able to continuously monitor and take into account customer } \\
\text { inputs and needs in the development of new functionalities for the } \\
\text { company's products } \\
\text { Fidelity card can, for example, be considered a way to improve relationship } \\
\text { with customers in shops, it can be used also to collect info about } \\
\text { customer behavior. Moreover it is necessary to provide clear and } \\
\text { reliable information on products and their characteristics (for example } \\
\text { on sustainability aspects) } \\
\text { Beside improvements in the Knowledge dimension, the ICT dimension } \\
\text { needs to be reinforced along the CNO, and this can be realized through } \\
\text { direct electronic communication to end-consumer using internet } \\
\text { interface and feedbacks } \\
\text { From the sustainability side information on environmental impact of } \\
\text { product and processes collected and structured have to be accessible and } \\
\text { included in the product data }\end{array}$ \\
\hline
\end{tabular}


Table 1 (continued)

\begin{tabular}{|c|c|}
\hline Building blocks & Dimensions (organizational, ICT, knowledge, sustainability) \\
\hline Capabilities & $\begin{array}{l}\text { Capabilities to be created in the CNO are: (1) services to members like } \\
\text { brokering, marketing services, market trends analysis (2) provide a } \\
\text { common base ICT infrastructure; ( } 3 \text { ) Support cooperative business } \\
\text { rules; (4) Offer assets (especially ICT and knowledge based) that will be } \\
\text { shared by members as for example services for supply network } \\
\text { management; (5) Evaluation, qualification and certification of members; } \\
\text { and (6) Manage the organization and its infrastructure } \\
\text { Reinforcement of the Knowledge and ICT dimension of the CNO based on } \\
\text { data coming from different partners of the CNO itself, both sales data } \\
\text { from retailers and market trends from stylists, and social networks } \\
\text { management } \\
\text { Capability to measure customer requirements is based on advanced systems } \\
\text { for dynamic measurement used at shop level. Knowledge dimension is } \\
\text { very important at this stage because it influences the capability of the } \\
\text { network. For what concerns sustainability, capabilities are related to } \\
\text { network process monitoring and integration of green production } \\
\text { practices }\end{array}$ \\
\hline $\begin{array}{l}\text { Multi-value } \\
\text { configuration }\end{array}$ & $\begin{array}{l}\text { Configuration of the value can be based on financial, technological, } \\
\text { knowledge, and social issues. In this case it is based mainly on } \\
\text { technological innovation for the product development and its realization } \\
\text { as well as on social value given by the possibility to address target } \\
\text { groups with new products improving their life conditions both in terms } \\
\text { of health and social inclusion } \\
\text { The configuration of the new product value is based on the collaboration } \\
\text { along the CNO of many different actors as stylists, designers, } \\
\text { production managers, as well as external professionals as medical } \\
\text { experts bringing their Knowledge on the TGs. Change the CNO } \\
\text { configuration (organizational dimension) involves all the actors of the } \\
\text { CNO also for sustainability evaluation }\end{array}$ \\
\hline Partnerships & $\begin{array}{l}\text { Different partners are necessary to cover some phases of the process } \\
\text { activities; partners are involved in standard as well as customized } \\
\text { production and are selected according to their skills, equipment, } \\
\text { reliability, and costs } \\
\text { Periodically (at the beginning of the season or yearly), long term } \\
\text { relationships should be activated with strategic suppliers and } \\
\text { outsourcers. Production of customized components should be based on } \\
\text { framework agreements which allows to activate time by time each } \\
\text { partner according to customer needs } \\
\text { The dimension involved in network formation and coordination is mainly } \\
\text { organizational. Also ICT infrastructure (such as integrated software or } \\
\text { machinery) is important in order to support network formation and } \\
\text { management }\end{array}$ \\
\hline
\end{tabular}


Table 1 (continued)

\begin{tabular}{ll}
\hline Building blocks & Dimensions (organizational, ICT, knowledge, sustainability) \\
\hline Cost & Main costs arising are on the technological innovation of the product \\
(search of new components and new materials) and new processes for \\
the development of customized components. From the ICT point of \\
view companies are not required to install any new tool but to use tools \\
available on a SaaS (Software as a Service) approach \\
Costs definition is based on the organization of the CNO and how partners \\
interact each other \\
Cost will be mainly for improving the ICT base of the network in order to \\
manage the partnership. Each company in the network will pay a fee to \\
use a collaborative platform where many different tools to support the \\
various stages of the design and production will be included \\
Revenues for the CNO are both from the sales of the products and from the \\
related services. Putting together competencies, companies can enlarge \\
revenues and the model to be applied can be based on sharing them \\
along the value network \\
Also in this case the organizational dimension is the most important one \\
because it is important to define clearly relationships along the \\
processes and related responsibility in order to allow a proper sharing of \\
revenues along the CNO according to given contributions
\end{tabular}

\subsection{Operative Level}

For what concerns the operative level, as an example, this chapter gives some hints on one of the processes of the tactical level, highlighting how to support the supply chain configuration phase in CM1 (Partner Search) with operative tools like partner profiling based on selection of intelligent indicators. Similar work has been done for all the other business processes developing tools and defining specific practices for each step.

Small series and customized products require new supply network management tools, able to support companies in collaborating with specialized partners, enabling to configure specific networks for each covered market niche, or, even, for each customer order, in case of personalized products. According to that, a company have to face different scenarios characterized by a very large number of small orders, each of them involving different partners, selected on the basis of their availability and capabilities. In this context, the process of partner profiling and monitoring, as well as the collaborative planning process, need to be supported by a partner search service based on easy to retrieve, easy to manage and reliable information. According to the needs of the analyzed companies and literature a set of KPIs have been defined for all the dimensions identified in the framework represented in Fig. 2 to be used for a multi-criteria partner search and selection. 


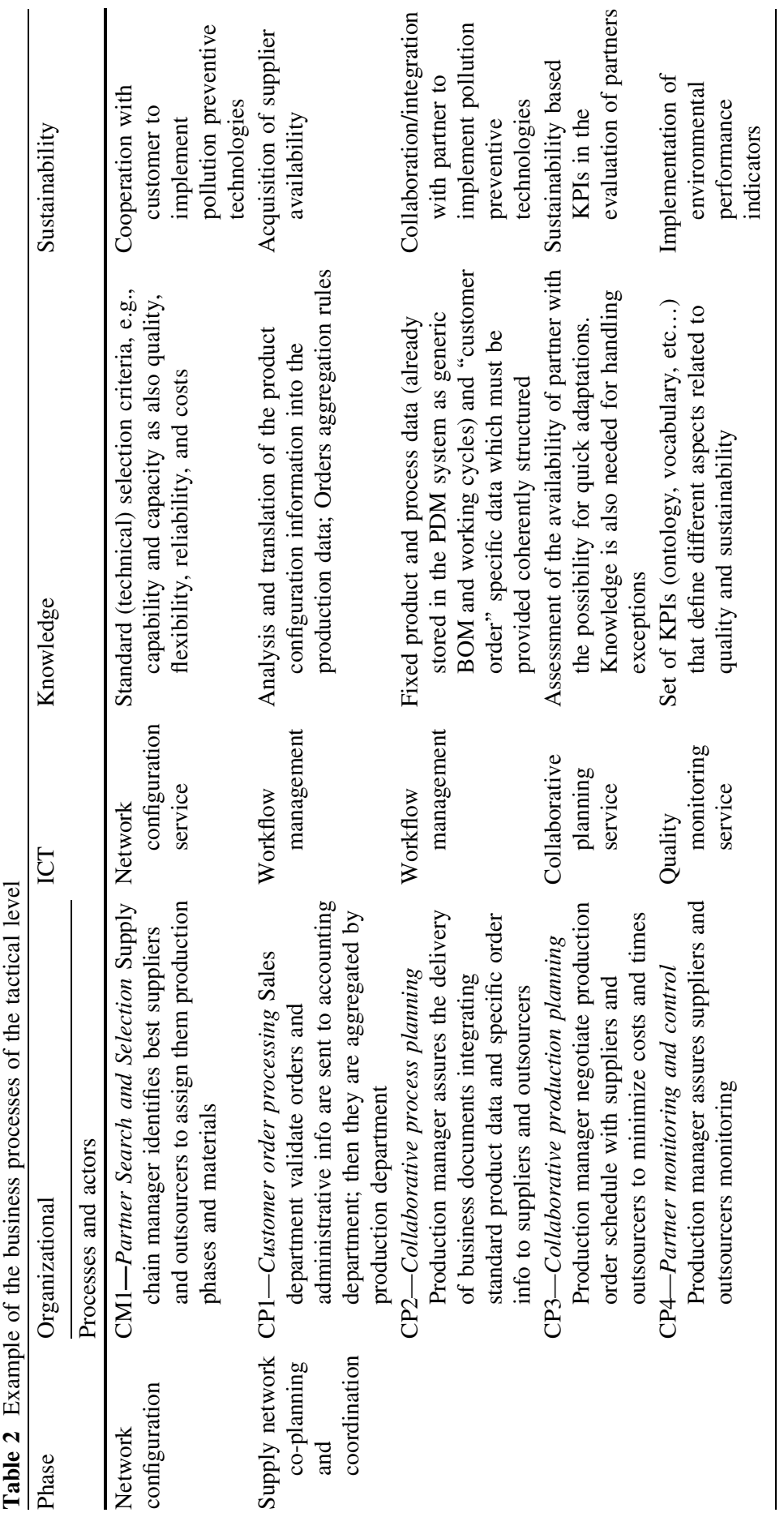




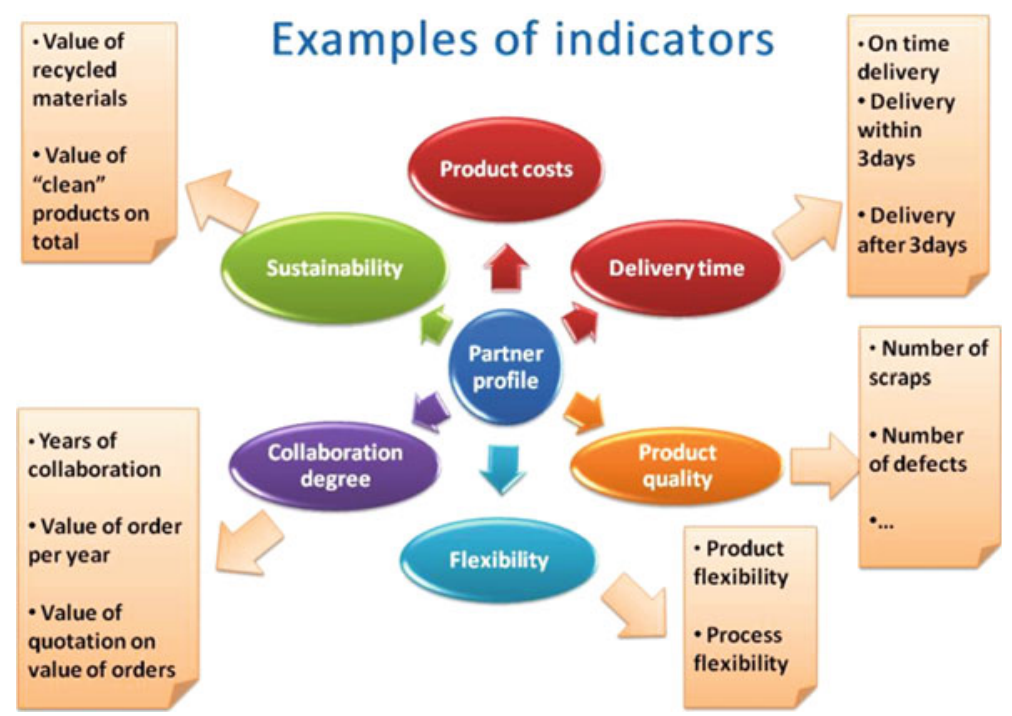

Fig. 2 Example of framework for the definition of partner profile

\section{Conclusions}

This work proposes a RM framework to create innovative collaborative environments enabling European fashion companies to produce and deliver small series of specialized and customized high value added products. The industrial and empirical nature of the RM framework guarantees full applicability of its guidelines.

In particular, the RM represents a formalization of a methodology that can be applied to companies with the support of methods and tools for product design, planning, production activities, and rapid manufacturing technologies. The RM aims to facilitate supply networks in managing consumers' data to understand their needs, involve consumers in product design and configuration, exchange consumers' data through adequate data models and secure systems, collaborate with suppliers, implement innovative manufacturing machines, monitor quality, and sustainability of products. The model has been applied to a real case of a fashion company willing to enter a new niche market. The instantiation made according to the three different levels of the RM started with the definition of the new Business Model and the description of the most relevant dimensions involved in its application concerned with the strategic level. Then the model enabled a revision and a formalization of the main business processes at the tactical level and provided operative support to this processes. In particular, the case of the partner profiling process is reported as an example to show how specific practices and guidelines can support the proper process implementation. Feedbacks collected from companies allowed to make a refinement of different aspects of the RM. 
For what concerns the specific implementation in the considered business case, even if the collaboration processes are still under revision, some improvements have already been reported by the network companies: the capability to increase the level of coordination among partners, the capacity to involve consumers through specific requirements included in product design and configuration all over the supply chain and the increased ability to monitor quality and eco-sustainability of products in the network (in terms of amount of information available on materials, production process, and practices along the network).

Acknowledgments This work has been partly funded by the European Commission through the FP7-2010-NMP-ICT-FoF Project CoReNet: "Customer-Oriented and Eco-Friendly Networks for Healthy Fashionable Goods" (Grant Agreement 260169). The authors wish to acknowledge the Commission for the support.

\section{References}

1. Dyer JH, Singh H (1998) The relational view: cooperative strategy and source of interorganizational competitive advantage. Acad Manage Rev 23(4):660-679

2. Camarinha-Matos LM, Boucher X, Afsarmanesh H (2010) Collaborative networks for a sustainable world. In: Proceedings of the 11th IFIP WG 5.5 working conference on virtual enterprises

3. Grefen P et al (2009) Dynamic business network process management in instant virtual enterprise. Comput Ind 60:86-103

4. Childerhouse P, Aitken J, Towill DR (2002) Analysis and design of focused demand chains. J Oper Manage 20(6):675-689

5. De Treville S, Shapiro RD, Roy D, Hameri AP (2004) From supply chain to demand chain: the role of lead time reduction in improving demand chain performance. J Oper Manage 21(6):613-627

6. Piller F, Tseng M (2003) New directions for mass customization. The customer centric enterprise. Advances in mass customisation. Springer, New York

7. Adler PS (2001) Market, hierarchy and trust: the knowledge economy and the future of capitalism. Organ Sci 12(2):215-234

8. Filos E, Banahan E (2001) Towards the smart organization: an emerging organizational paradigm and the contribution of the European RTD programs. In: Journal of Intelligent Manufacturing, vol 12(2). Springer Netherlands, pp 101-11

9. Glaser B, Strauss A (1967) Grounded theory: the discovery of grounded theory. Aldine, Chicago

10. Eisenhardt KM (1989) Building theories from case study research. Acad Manag Rev 14(4):532-550

11. Yin RK (1994) Case study research. Design and methods. Sage, Thousand Oaks

12. Osterwalder A (2004) The business model ontology a proposition in a design science approach. PhD-Thesis, Lausanne University, Switzerland

13. Loss L, Crave S (2011) Agile business models: an approach to support collaborative networks. Prod Plan Control Manage Oper 22(5-6):571-580

14. Romero D, Galeano N et al (2006) Towards the definition of business models and governance rules for virtual breeding environments network-centric collaboration and supporting frameworks, vol 224. Springer, Boston, pp 103-110

15. Plantin S (2008) Orange labs R\&D internal methodology for building business models 